\title{
Superhydrophobic Surface Fabricated on Carbon Steel Substrate by Zinc Electrodeposition for Prevention of Corrosion
}

\author{
Liping Wang ${ }^{1,2, *}$, Lei Zhuang ${ }^{2,3}$,Gang Chen ${ }^{2}$, Dong Leng ${ }^{2,3}$, Jian wang ${ }^{2,3}$, Li Cheng ${ }^{2,3}$, Wei Liu ${ }^{2,3}$, Jianbo Wang ${ }^{2}$ and \\ Baorong Hou ${ }^{1}$ \\ ${ }^{1}$ Key Laboratory of Marine Environmental Corrosion and Bio-fouling, Institute of Oceanology, Chinese Academy of Sciences, Qingdao \\ 266071, China \\ ${ }^{2}$ Rizhao Port Group Co., Ltd, Rizhao 276826, China \\ ${ }^{3}$ Shandong Harbour Engineering Group Co., ltd, Rizhao 276826, China
}

\begin{abstract}
A facile, low cost, and relatively environmental friendly method was presented for the fabrication of superhydrophobic surface on carbon steel substrate. The superhydrophobic surface was obtained by zinc electrodeposition and chemical modification with ethanolic stearic acid. The wettability of the superhydrophobic surface was measured by a water contact angle (WCA) with a highest value of 155.7॰. The morphology of the fabricated film was characterized by scanning electron microscopy (SEM). The chemical composition of the fabricated surface was analysed by energy dispersive spectrometer (EDS) and fourier transform infrared spectroscopy (FTIR), respectively. The corrosion resistance of the carbon steel substrate was measured by potentiodynamic polarization test in $3.5 \mathrm{wt} \% \mathrm{NaCl}$ solution. The electrochemical measurements show excellent corrosion resistance, which may have promising applications in anticorrosion of carbon steel.
\end{abstract}

\section{Introduction}

Carbon steel, a common kind of metallic material, has been widely used in many applications such as architectural engineering, bridges, railways, vehicles, ships and various machinery manufacturing industries and other areas owing to its outstanding mechanical performance, low cost, perfect electrical conductivity and so on $[1,2]$. Due to the high chemical reactivity, carbon steel was easy to be corroded in a wet environment, causing lots of economic losses and security issues [3]. To reduce these problems, zinc was usually used to protect steel from corrosion by electrodeposition $[4,5]$. At present, the galvanizing process is still one of the most economic and efficient technology for carbon steel protection. However, chromic acid salt was usually used for passivation of zinc to improve the performance of corrosion resistance, which may cause critical problems in environment [6].

In recent years, superhydrophobic surface technique have been extensively developed and applied in the selfcleaning [7-9], oil-water separation [10-13] and anticorrosion [14-16]. Generally, the superhydrophobic surface possess a water contact angle (CA) more than $150^{\circ}$ and a sliding angle (SA) lower than $10^{\circ}$, which can be commonly found from lotus leaf, butterfly wings and mosquito eyes in nature [17-19]. These superhydrophobic states grant excellent anti-corrosion properties to the metal material that has attracted our great interest. In this work, superhydrophobic surface was fabricated on carbon steel via chemical modification after zinc electrodeposition. This kind of method was simple and did not require complex instruments. Moreover, the fabricated film shows excellent anticorrosion and the entire process of fabrication was relatively environmental friendly without any toxic substances. Therefore, the developed method will be one of the best substitute technologies for the traditional passivation of galvanized zinc.

\section{Experiment}

Carbon steel (Q235), purchased from Baosteel Group Corp., and was clipped into pieces of $200 \mathrm{~mm} \times 150 \mathrm{~mm} \times$ $2 \mathrm{~mm}$ as samples. Zinc chloride, potassium chloride, boric acid and stearic acid with analytical grade were obtained from Sinopharm Chemical Reagent Co.,Ltd).

To remove the iron rust and other oxide film, the substrates were polished by sand paper with different mesh number of $400,800,1200$, and 2000 successively and cleaned with acetone, ethanol, deionized water orderly and then air dried. The carbon steel and a $300 \mathrm{~mm} \times 20 \mathrm{~mm} \times 2 \mathrm{~mm}$ pure Zinc has been chosen as cathode and counter electrode, and $120 \mathrm{~g} / \mathrm{L}$ zinc chloride, $60 \mathrm{~g} / \mathrm{L}$ potassium chloride, $15 \mathrm{~g} / \mathrm{L}$ boric acid aqueous solution has been chosen as electrolyte. In the electrodeposition, a direct current power was used to supply a constant current with the bath voltage of $4.0 \mathrm{~V}$ at room temperature for $20 \mathrm{~min}$. After the electrodeposition, the treated carbon steel substrates

\footnotetext{
* Corresponding author: wanglp88@126.com
} 
were cleaned with deionized water and dried with cold air, followed by immersion into $0.05 \mathrm{~mol} / \mathrm{L}$ stearic acid. Then the pieces were dried at $105{ }^{\circ} \mathrm{C}$ for $1 \mathrm{~h}$, the superhydrophobic $\mathrm{Zn}$ surface on carbon steel was obtained.

The wettability properties of the prepared superhydrophobic substrates were measured by a contact angle analyser (JCY-2, Shanghai FangRui Instrument $\mathrm{CO}$,.LTD) with $5 \mu \mathrm{L}$ water droplet at room temperature. All the results were taken from the mean of the five different measurements. The morphologies of the superhydrophobic film were characterized by scanning electron microscope (SEM, Carl Zeiss sigma300, Germany) with an energy dispersive spectrometer (EDS). The chemical composition of the surface was characterized by a Fourier transform infrared spectroscopy (FTIR, Nexu Thermo Fisher Scientific Inc. USA). The corrosion resistance of the samples was investigated by potentiodynamic polarization curves at a scan rate of $1 \mathrm{mV} / \mathrm{s}$ and potential from $-250 \mathrm{mV}$ to +250 $\mathrm{mV}$ vs Open Circuit Potential, which were carried out using by Gamry Reference1000 (USA). All the electrochemical experiments were measured in $3.5 \mathrm{wt} \%$ $\mathrm{NaCl}$ aqueous solution at a room temperature.

\section{Result and discussion}

\subsection{The morphology of the fabricated film}

As is well known, the excellent superhydrophobic properties of the substrate depend on its special microstructure and compositions, corresponding to the phenomena of "Capillarity" and "Cushion effect" [20]. Figs. 1a-1c shows the SEM images of bare carbon steel, carbon steel with electrodeposited $\mathrm{Zn}$ and superhydrophobic Zn surface.

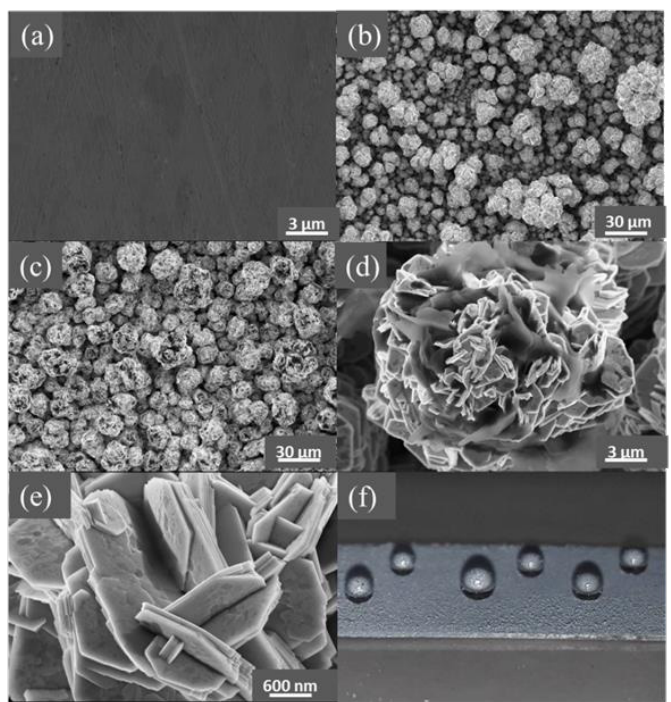

Figure 1. SEM images of the sample (a) bare carbon steel, (b) carbon steel after $\mathrm{Zn}$ electrodeposition, (c, d, e) carbon steel after $\mathrm{Zn}$ electrodeposition and modification, (f) Photograph of water droplets on the superhydrophobic film.

An approximately smooth flat surface has been shown in Fig.1a. Compare to Fig.1a, it was clear seen from Fig.1b and Fig.1c that a rough surface has been fabricated in the substrate on account of large amounts of electrodeposited protrusive $\mathrm{Zn}$ microparticles. Thus, we may find several micron sized hills and valleys in Fig.1b and Fig.1c. Along with the amplification, it may be found from Fig.1d and Fig.1e that multiple nanosized embossments exist on the surface. The fabricated mironano structures allow air to be trapped within the surface, which can effectively prevent water drop from the substrate. Fig.1f shows the photograph of carbon steel after $\mathrm{Zn}$ electrodeposition and modification with steric acid. The water on the surface are all of sphere shapes, that revels the successful superhydrophobic fabricated on the carbon steel substrate.

\subsection{The composition of the fabricated film}

The composition of the pure carbon steel and samples after electrodeposition and modification was analysed by EDS and FTIR, and results were shown in Fig.2 and Fig.3. It may be seen from Fig.2a that the carbon steel was mainly composed of element $\mathrm{C}$ and $\mathrm{Fe}$ with small amount of $\mathrm{O}$, which may be owing to the steel oxidation. Fig.2b shows that the carbon steel was completely covered by $\mathrm{Zn}$ after electrodeposition. Compared to Fig.2b, the $\mathrm{Zn}$ surface after modification in Fig.2c contained the additional element $\mathrm{C}$ and $\mathrm{O}$, revealing that the stearic acid has successfully assembled to the surface. Fig.3a and Fig.3b show the FTIR spectra of carbon steel after $\mathrm{Zn}$ electrodeposition and carbon steel after $\mathrm{Zn}$ electrodeposition and modification with stearic acid in the range of 4000 to $500 \mathrm{~cm}^{-1}$, respectively. We may find an approximate smooth curve in Fig.3a with unnoticeable absorption peak. Compared to Fig.3a, an obvious series of absorption peaks were detected and shown in Fig.3b. In the high frequency region, the peak at around 2916 and $2847 \mathrm{~cm}^{-1}$ correspond to the methyl and methylene stretching vibration absorption peaks of stearic acid, respectively[21]. The significant peaks present at 1537 and $1468 \mathrm{~cm}^{-1}$ was also observed, assigned to $\mathrm{COO}-$ groups of $\mathrm{CH}_{3}\left(\mathrm{CH}_{2}\right) \mathrm{COO}$ - on the carbon steel after $\mathrm{Zn}$ electrodeposition and modification with stearic acid. It is further indicated that the stearic acid had successfully assembled on this $\mathrm{Zn}$ coating surface, which contributed to the decrease in the surface energy of this coating.

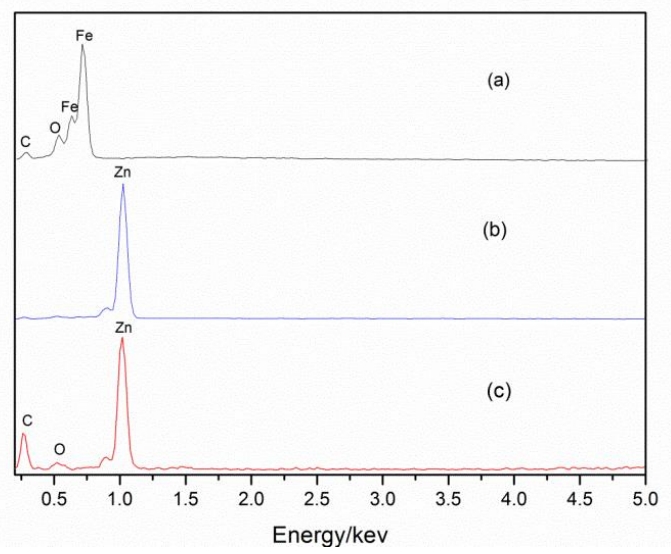

Figure 2. EDS spectra of the sample (a) bare carbon steel, (b) carbon steel after $\mathrm{Zn}$ electrodeposition, (c) carbon steel after $\mathrm{Zn}$ electrodeposition and modification. 


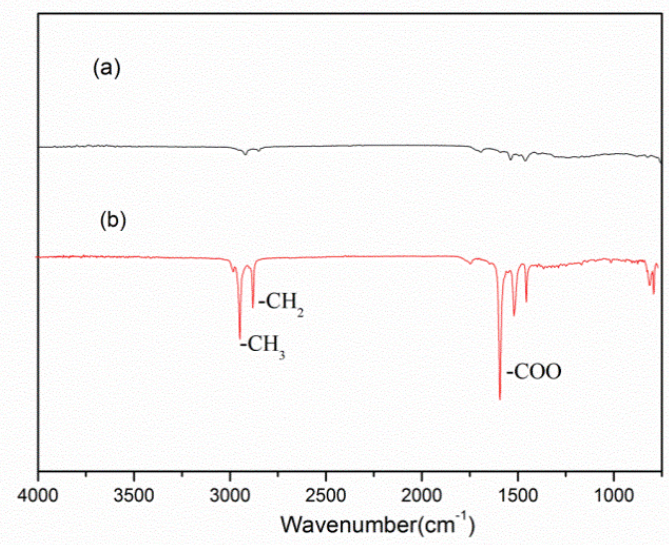

Figure 3. FTIR spectra of the sample (a) carbon steel after $\mathrm{Zn}$ electrodeposition, (b) carbon steel after $\mathrm{Zn}$ electrodeposition and modification

\subsection{The effect of current density on the wettability of the fabricated film}

In order to study the effect of current density on the wettability of the superhydrophobic $\mathrm{Zn}$ surface, the carbon steel was electrodeposited with a constant bath voltage of $4.0 \mathrm{~V}$ for 20 min under different current density, and all the results were shown in Fig.4. It can be seen from Fig. 4 that the water contact angle of the fabricated surface increases significantly with the enhance of current density, and reaches the highest value of $155.7^{\circ}$ when the current density added up to $5 \mathrm{~A} / \mathrm{dm}^{2}$. After that, the water contact angle decreases slowly with the growing current density. It can be concluded that the electrodeposition current density was an important factor that affects the superhydrophobic performance.

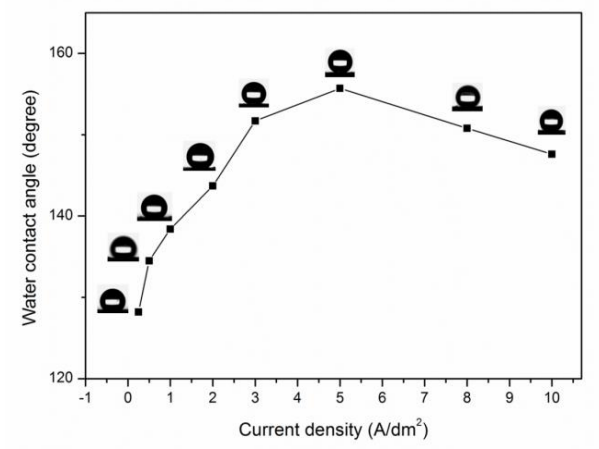

Figure 4. Contact angle of the superhydrophobic $\mathrm{Zn}$ surface with different current densities.

\subsection{The corrosion property of the fabricated} film

In order to evaluate the corrosion property of the prepared samples, the potentiodynamic polarization tests on bare carbon steel, carbon steel after $\mathrm{Zn}$ electrodeposition and superhydrophobic $\mathrm{Zn}$ surface were investigated in $3.5 \mathrm{wt} \% \mathrm{NaCl}$ aqueous solution. All the experimental data were plotted in Fig.5. The corrosion potential $\left(E_{\text {corr }}\right)$, the corrosion current intensity $\left(I_{\text {corr }}\right)$ and the corrosion rate $\left(v_{\text {corr }}\right)$ were obtained from the polarization curves in Fig.5 according to Tafel extrapolation. The protection efficiency $(\eta)$ of carbon steel after $\mathrm{Zn}$ electrodeposition and superhydrophobic $\mathrm{Zn}$ surface were calculated by the equation[22]:

$$
\eta=\left(I_{\text {corr }}-I_{\text {corr }}\right) / I_{\text {corr }} \times 100 \%
$$

Where $I_{\text {corr }}$ was the corrosion current of the bare carbon steel, $I_{\text {'corr }}$ presents the corrosion current of carbon steel after $\mathrm{Zn}$ electrodeposition or superhydrophobic $\mathrm{Zn}$ surface. In addition, the polarization resistances $(R)$ was calculated using by Stern-Geary equation $[23]$ :

$$
R=\left(b_{\mathrm{a}} \cdot b_{\mathrm{c}}\right) / 2.303 /\left(b_{\mathrm{a}}+b_{\mathrm{c}}\right) / I_{\text {corr }}
$$

Where $b_{\mathrm{a}}$ and $b_{\mathrm{c}}$ were the slopes $(\Delta E / \log I)$ of the anodic and cathodic by Tafel fitting. All the values were listed in Table 1.

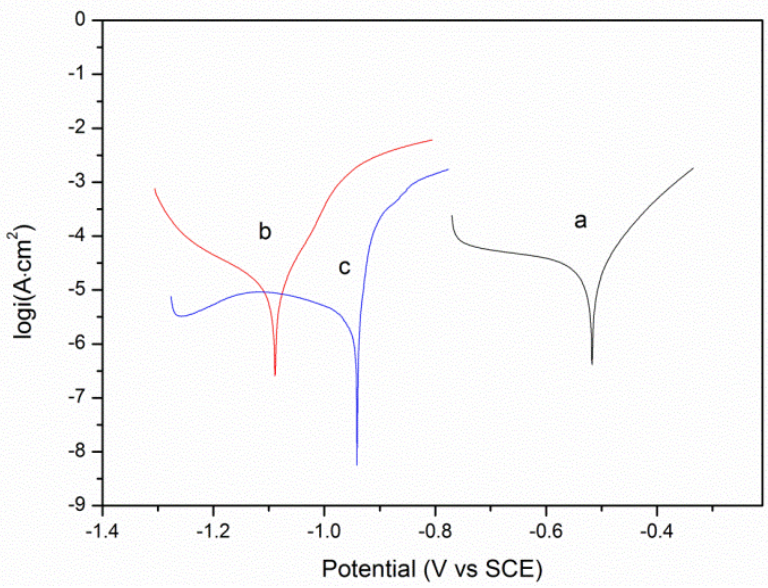

Figure 5. Polarization curves of the sample (a) carbon steel after Zn electrodeposition, (b) carbon steel after Zn electrodeposition and modification.

Table 1. Comparison of $E_{\text {corr, }} I_{\text {corr, }} \mathrm{v}_{\text {corr }}, \eta$ and $R$ of different samples

\begin{tabular}{cccccccc}
\hline Samples & $E_{\text {corr }}(\mathrm{mv})$ & $I_{\text {corr }}\left(\mathrm{A} / \mathrm{cm}^{2}\right)$ & $v_{\text {corr }}(\mathrm{mm} / \mathrm{a})$ & $b_{\mathrm{a}}(\mathrm{V} / \mathrm{dec})$ & $b_{\mathrm{c}}(\mathrm{V} / \mathrm{dec})$ & $\eta(\%)$ & $R\left(\mathrm{k} \Omega \cdot \mathrm{cm}^{2}\right)$ \\
\hline Bare carbon steel & -517 & $3.57 \times 10^{-5}$ & 16.32 & 0.1014 & 0.7694 & & 1.09 \\
Electrodeposited Zn surface & -1090 & $1.35 \times 10^{-5}$ & 6.19 & 0.0600 & 0.1577 & 62.18 & 1.40 \\
Superhydrophobic Zn surface & -941 & $3.64 \times 10^{-7}$ & 0.17 & 0.0063 & 0.0106 & 98.98 & 4.71 \\
\hline
\end{tabular}

From Table 1 we may find that the corrosion potential of carbon steel after $\mathrm{Zn}$ electrodeposition was lower than bare carbon steel, which means an easier corrosion for $\mathrm{Zn}$. The result verifies that carbon steel can be protected by sacrificial anodes of $\mathrm{Zn}$. The corrosion potential of electrodeposited $\mathrm{Zn}$ was increased from 1090 to $-941 \mathrm{mv}$ after modification with stearic acid, which means a fewer degree of corrosion of superhydrophobic $\mathrm{Zn}$ surface. The value of corrosion currency intensity and the corrosion rate of the fabricated 
superhydrophobic surface was $3.64 \times 10^{-7} \mathrm{~A} / \mathrm{cm}^{2}$ and 0.17 $\mathrm{mm} / \mathrm{a}$, which was much lower than electrodeposited $\mathrm{Zn}$ surface $\left(1.35 \times 10^{-5} \mathrm{~A} / \mathrm{cm}^{2}, 6.19 \mathrm{~mm} / \mathrm{a}\right)$ and pure carbon steel $\left(3.57 \times 10^{-5} \mathrm{~A} / \mathrm{cm}^{2}, 16.32 \mathrm{~mm} / \mathrm{a}\right)$. The calculated protection efficiency of superhydrophobic $\mathrm{Zn}$ surface was $98.98 \%$ compared with the value of $62.18 \%$ of the electrodeposited Zn surface without modification. It can be confirmed the fact that the superhydrophobic $\mathrm{Zn}$ surface owns the best anticorrosion properties. Moreover, the polarization resistance of the superhydrophobic $\mathrm{Zn}$ surface was as high as $4.71 \mathrm{k} \Omega \cdot \mathrm{cm}^{2}$, which was nearly 4.3 times of the bare carbon steel and 3.3 times of the electrodeposited Zn surface without modification. From the above, the superhydrophobic $\mathrm{Zn}$ surface has the best corrosion protective properties from various corrosion parameters, which has great potential applications in the field of carbon steel protection.

\section{Conclusion}

In this work, a method of fabrication of superhydrophobic surface on carbon steel substrate by $\mathrm{Zn}$ electrodeposition and chemical modification with stearic acid has been presented. SEM results show that the superhydrophobic property was caused by the fabrication of mico-nano structure. The asprepared superhydrophobic $\mathrm{Zn}$ surface can exhibit excellent reversible wettability controlled by changing electrodeposited current density. In addition, potentiodynamic polarization test shows the superhydrophobic $\mathrm{Zn}$ surface has the best anticorrosion property compared with bare carbon steel and the electrodeposited $\mathrm{Zn}$ surface without modification. The established method was facile, low cost, and relatively environmental friendly, and can be suitable for the protection of carbon steel.

\section{Acknowledgments}

This work was financially supported by Shandong Postdoctoral Fund (2017157).

\section{References}

1. A. Fihri, E. Bovero, A. Al-Shahrani, A. Al-Ghamdi, G. Alabedi, Colloids and Surfaces aPhysicochemical and Engineering Aspects, 520 (2017) 378-390.

2. H. Gao, S. Lu, W. Xu, S. Szunerits, R. Boukherroub, Rsc Advances, 5 (2015) 40657-40667.

3. G.N. Kirby, Chemical Engineering, 86 (1979) 72-84.

4. K. Alipour, F. Nasirpouri, Rsc Advances, 7 (2017) 51879-51887.

5. O.S.I. Fayomi, A.P.I. Popoola, Surface Engineering and Applied Electrochemistry, 51 (2015) 76-84.

6. M. Dong, X. Xue, A. Kumar, H. Yang, M.I. Sayyed, S. Liu, E. Bu, Journal of Hazardous Materials, 344 (2018) 602-614.
7. H. Bagheri, M. Aliofkhazraei, H.M. Forooshani, A.S., Applied Surface Science, 436 (2018) 11341146.

8. J. Cremaldi, B. Bhushan, Journal of colloid and interface science, 518 (2018) 284-297.

9. Y. Xing, Y. Xue, J. Song, Y. Sun, L. Huang, X. Liu, J. Sun, Applied Surface Science, 436 (2018) 865872.

10. Z. Guo, F. Yang, , Fabrication and Application, (2017) 245-272.

11. R.K. Gupta, G.J. Dunderdale, M.W. England, A. Hozumi, , Journal of Materials Chemistry A, 5 (2017).

12. Y. Xiang, Y. Si, Y. Xin, Z. Guo , Chemistry Letters, 46 (2017) 1393-1395.

13. X. Zhu, Z. Zhang, B. Ge, X. Men, X. Zhou, Q. Xue, Journal of colloid and interface science, 432 (2014) 105-108.

14. C. Lv, H. Wang, Z. Liu, W. Zhang, C. Wang, R. Tao, M. Li, Y. Zhu, Applied Surface Science, 435 (2018) 903-913.

15. C.-W. Yao, D. Sebastian, I. Lian, O. Gunaydin-Sen, R. Clarke, K. Clayton, Coatings, 8 (2018).

16. S. Zhou, X. Zhu, Q. Yan, Surface and Interface Analysis, 50 (2018) 290-296.

17. Y. Qing, C. Yang, C. Hu, Y. Zheng, C. Liu, Applied Surface Science, 326 (2015) 48-54.

18. L.-K. Wu, X.-F. Zhang, J.-M. Hu, 85 (2014) 482487.

19. D. Yu, J. Tian, J. Dai, X. Wang, Electrochimica Acta, 97 (2013) 409-419.

20. Y.J. Cho, H. Jang, K.-S. Lee, D.R. Kim, Applied Surface Science, 340 (2015) 96-101.

21. Y. Liu, S. Li, J. Zhang, Y. Wang, Z. Han, L. Ren, Chemical Engineering Journal, 248 (2014) 440-447.

22. B.V.A. Rao, M.Y. Iqbal, B. Sreedhar, Electrochimica Acta, 55 (2010) 620-631.

23. J. Tan, J. Hao, Z. An, C. Liu, International Journal of Electrochemical Science, 12 (2017) 40-49. 